\title{
A case study on Zomato - The online Foodking of India
}

\author{
Ashok Panigrahi $^{1 *}$, Abhijit Saha ${ }^{2}$, Aditya Shrinet ${ }^{3}$, Mehul Nauityal ${ }^{4}$, Vidur Gaur \\ ${ }^{\mathbf{1}}$ Associate Professor, ${ }^{2-5}$ Student MBA(Tech), ${ }^{1}$ Dept. of Technology Management, ${ }^{2-5}$ Dept. of Civil Engineering, NMIMS, Shirpur, \\ Maharashtra, India
}

*Corresponding Author: Ashok Panigrahi

Email: ashok.panigrahi@nmims.edu

\begin{abstract}
Zomato started in 2008 underneath the name, 'Foodiebay' to begin with. Later in 2010, it had been renamed to 'Zomato'. Constantly 2011, Zomato extended to increasingly urban regions the country over in Mumbai, Delhi NCR, Chennai, Bangalore, Kolkata and Pune. After that in the year 2012, the corporate extended working all around in various countries like the UAE, Qatar, Sri Lanka, UK, South Africa and Philippines. In the year 2013, Zomato had moved their organizations in Brazil, New Zealand, Turkey and Indonesia, with its applications and site open in various lingos isolated from English. After that in April 2014, Zomato impelled its organizations in Portugal Republic, trailed by Canada, Lebanon and Ireland around a similar time. The acquiring of Settled - based sustenance zone 'Urban spoon' signified the organization's passageway into the United States, Canada and Australia, and conveyed it into direct test with 'Wail', 'Zagat' and 'Open Table'. With the introduction of .xxx zones in 2011, Zomato also impelled 'zomato.xxx', a site dedicated to finding spot to eat near to your territory. It later moved a print adjustment of the site substance named, 'Citibank Zomato Restaurant Guide', got together with Citibank in May 2012, at any rate later it was halted.
\end{abstract}

Keywords: Zomato, Online food, Cloud kitchen, Bistros.

\section{Introduction}

Zomato is accomplice to aggregator of Indian bistro and transport of sustenance leave fire up space arranged in the year 2008. It had been begun by Pankaj Chaddah and Deepinder Goyal. It gives data, menu card and reviews from customers of diners, and additionally it has transport of sustenance choices from bistros that are accessory in picked urban regions. As on 2016, the gave organizations is conceivable in twenty-four countries. Throughout the years, it has changed over itself into an online nourishment conveyance stage. Individuals would now be able to arrange nourishment from the cafés close to them utilizing their application or site. Zomato has conveyance administrators who get the request from the restaurant and convey it to the location gave by the client.

\section{Trade Details}

In February 2017, Zomato in an affiliation's blog, clarified cloud kitchen. With its cloud kitchen, the corporate expected to assist bistros with developing their substance without accomplishing any affixed cost. Later in September 2017, Zomato guaranteed that the corporate had "turned accommodating" inside 24 nations worked in and reported that the "zero commission model" to be presented for colleague bistros.

Towards the bit of the arrangement, continued taking updates from its dynamic clients by not using referees to check and make critical updates. Bistro data was not empowered. Clients of the application announced issues with new decisions to pay for requesting. The application was strengthened especially to continue working with extra excellent employable structures. Zomato compelled its disasters by $34 \%$ to ₹389 Cr for the budgetary year 201617 , from ₹590.1Cr in the earlier year 2015-16.

In September 2019, Zomato laid off most basic number (541 individuals) of operators basically $10 \%$ of workforce wearing out back exercises like client care, seller and transport colleague bolster limits.

\section{Founders}

Mr. Deepinder Goyal is the Founder and Chief Executing Officer (CEO) of Zomato. Before starting 'Zomato' (earlier Foodiebay), Deepinder filled in as an organization master with 'Bain and Company' in New Delhi. It was at Bain where Deepinder thought about an online restaurant information and organization in the wake of seeing the enthusiasm for menu cards among his partners working at Bain. He left Bain in 2008 to begin 'Zomato' (earlier foodiebay) out of his condominium and has since overseen framework and thing headway. Deepinder graduated with a Mathematics and Computing degree from IIT Delhi in 2005 and hails from Muktsar in Punjab.

Pankaj is the Co-Founder and Chief Operating Officer (COO) of Zomato. Before joining Zomato, Pankaj moreover worked with 'Bain and Company', in New Delhi. In his present employment, Pankaj oversees arrangements and exercises for Zomato in neighborhood and worldwide markets. He besides had in like manner been liable for all 
compact headway and course across over stages. Pankaj graduated with a degree in mechanical structuring from IIT Delhi in 2007.

\section{Values}

1. Resilience: Zomato push themselves from the far side to their skills when they faced with are times. When they foresee uncertainty, they address it solely with flexibility.

2. Acceptance: Feedback isn't taken personally, they break it into positive items and figure out on each and every element even more effectively.

3. Ownership: Folks at Zomato do not work 'for' Zomato, they work 'with' Zomato. They treat every problem as our own, take accountability and drive the amendment.

4. Humility: It is usually 'us' over 'me'. Zomato do not lose themselves in pride or confidence throughout individual successes, however target on being our simple selves in every which way.

5. Spark: Zomato believe in, stand for and are converter of our culture - both, within Zomato and outside with all their stakeholders.

6. Judgement: It is not their skill that show who we truly are - it's their choices. They aim to induce these right, a minimum within the majority of the cases.

\section{Investments}

Between 2010-13, Zomato raised for the most part $\$ 16.7$ million in Info Edge India, giving them a stake of $57.9 \%$ in Zomato. By Nov 2013, it increased an extra \$37 million from Info Edge India and Sequoia Capital.

In November 2014, Zomato finished another round in financing of $\$ 60$ million in a post-money evaluation of $\$ 660$ million. This round in financing is being driven together by Vy Capital and Info Edge India, with partnership from Sequoia Capital.

In April 2015, Vy Capital, Info Edge India and Sequoia Capital drove another round in financing for $\$ 50$ million. This was trailed by another $\$ 60$ million financing driven by Temasek, a Singapore government adventure association, close by Vy Capital in September.

In October 2018, Zomato increased \$210 million from Alibaba's portion partner Ant Financial. Underground creepy crawly Financial got a proprietorship stake of over $10 \%$ of the association as a component in the round, which regarded Zomato at around $\$ 2$ billion. Zomato had in like manner raised an extra $\$ 150$ million from Ant Financial earlier in 2018.

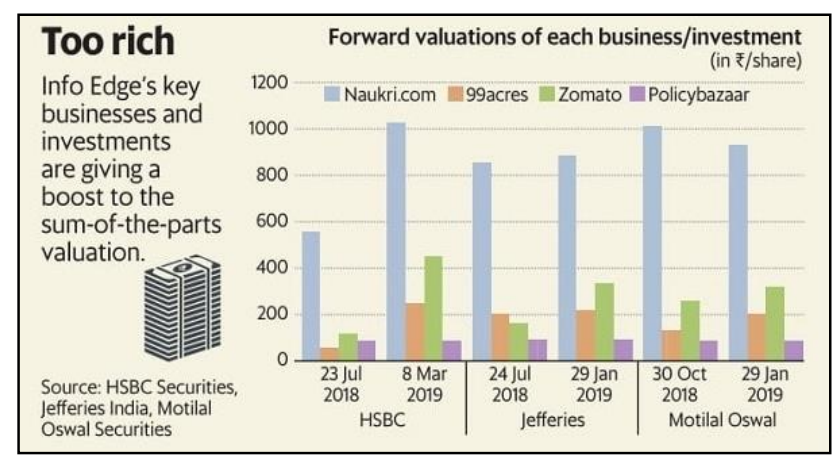

https://www.livemint.com/market/mark-to-market/are-infoedge-investors-betting-too-much-on-zomato-valuations1553444112230.html

\section{Market Share}

HSBC global investigation has esteemed Zomato at \$3.6 billion (Rs25,000 crore), around 70\% higher than the valuation credited to the eatery disclosure and nourishment conveyance firm once it raised capital as of late.

The hop in valuation moreover pushes Zomato sooner than its furious adversary Swiggy that was esteemed at $\$ 3.3$ billion post a $\$ 1$ billion financing it was done on December 2016. In a nitty gritty report on Info Edge, HSBC said Zomato's business has changed on a very basic level, with sustenance conveyance currently giving about $70 \%$ of absolute income.

Given the extent of its ongoing intensification and the requirement for further financing, we esteem Zomato on a lower income premise, at $\$ 3.6$ billion(at a negligible 9\% premium to its rival Swiggy as of the most recent round of subsidizing) versus $\$ 0.9$ billion prior because of modification of the center of HSBS. Zomato has an invested in a ton of amounts of energy in Search Engine Optimization.

According to Uber suggest information, it positions in India for 816,952 catchphrases as on July 2019. It's natural traffic is $6,719,882$ clients for every month. These details are truly astounding.

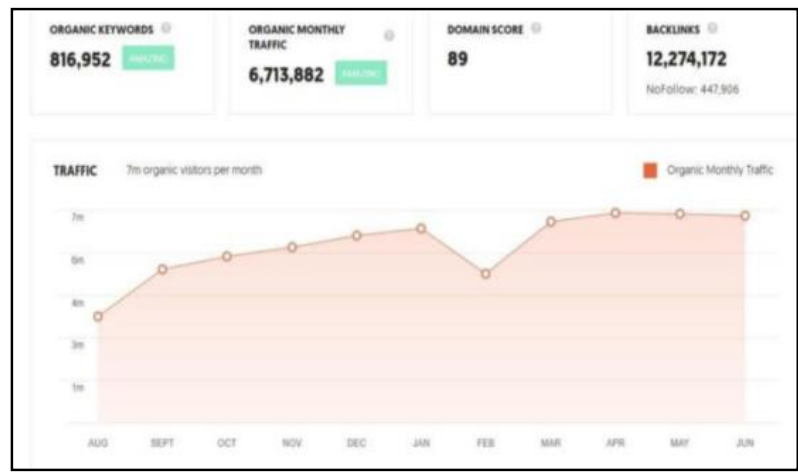

https://iide.co/case-studies/zomato-digital-marketingstrategy/ 
Zomato gets back links from 12,274,172 extraordinary areas. It likewise gets 233 backlinks from high power areas like.gov and.edu spaces. This builds the domain authority of Zomato's area and encourages it rank higher.

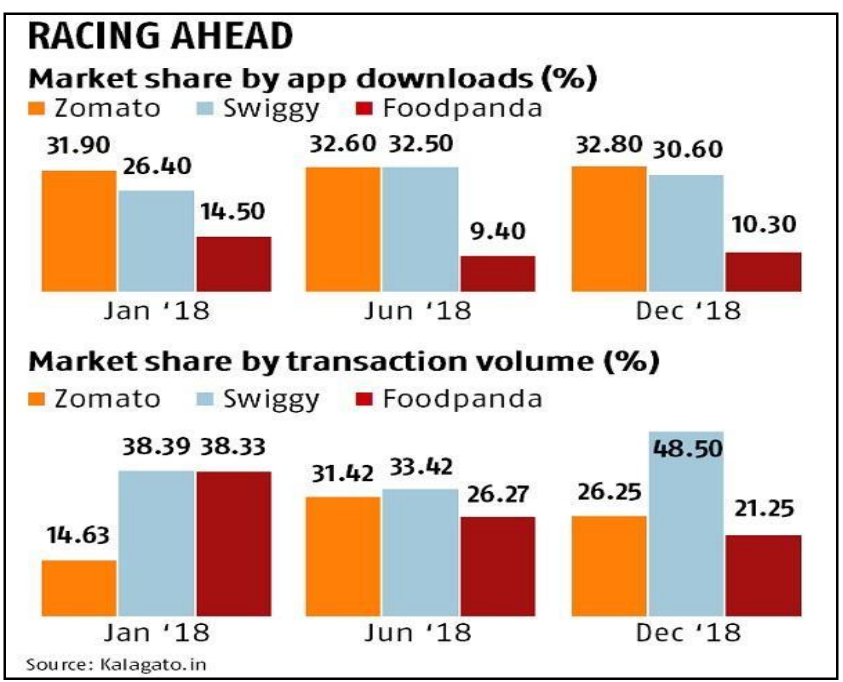

http://kalagato.in

\section{Revenue Model}

Zomato open with astonishing posting cafés, Static menu and getting outlines from clients about the sustenance served and their experience. This made an encompassing for customers and sustenance point and Advertising and maintained posting of bistro are the vital compensation getting plan. Zomato in addition started with online sustenance referencing and development in any case its lone open in Top metro urban zones and premium bistros and Zomato charges from 10-15\% for electronic referencing and further charges on transport by Zomato.

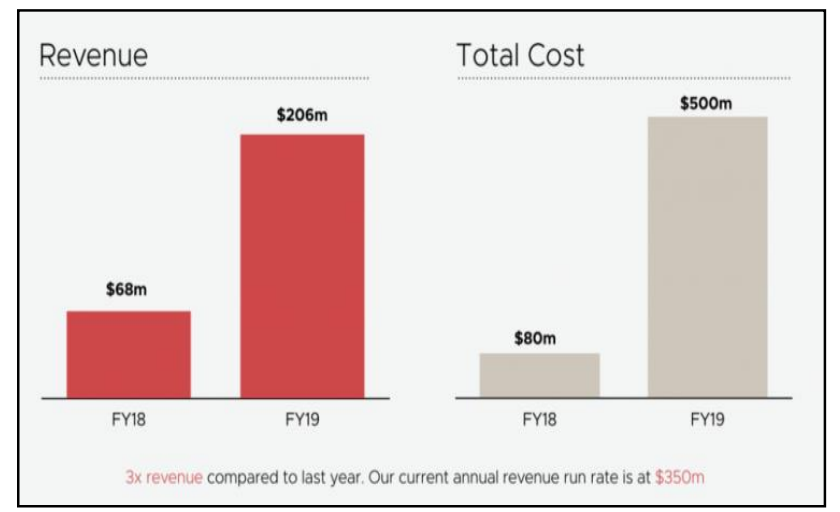

https://www.zomato.com/blog/annual-report-19

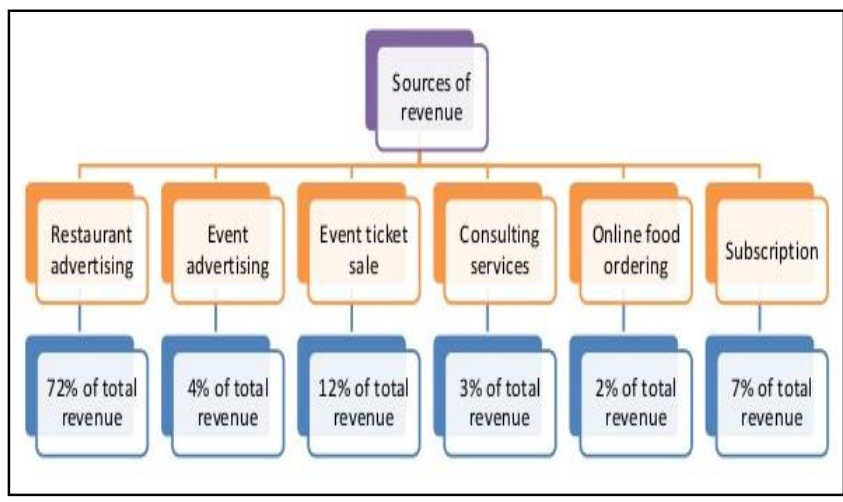

https://futureworktechnologies.com/how-zomato-worksbusiness-revenue-model

Three years prior, publicizing spoke to $100 \%$ of our income and core interest. Today, we are to a great extent an exchanges organization - 85\% of our income in March'19 was driven by exchanges.

Development in exchanges tested our psychological models of promoting being a different line of business. With increment in commissions, our advertisements income would endure a shot, and the other way around. In that soul, we realigned our business deeply precepts of the nourishment business. We quit considering publicizing income as an independent P\&L a year ago, and we currently think about our business as a mix of three key enormous columns - Delivery, Dining Out, and Sustainability.

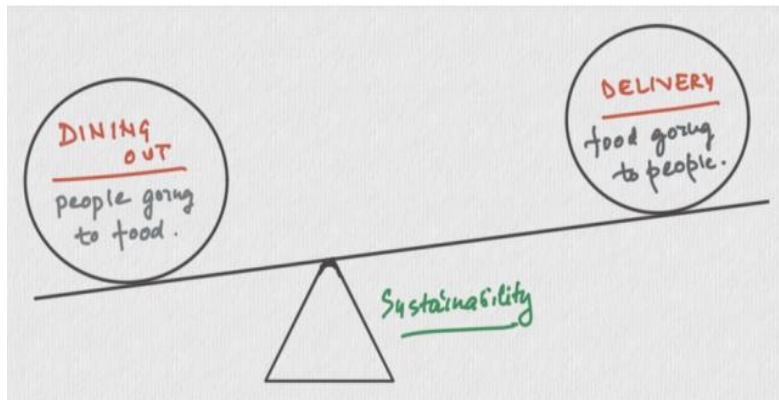

https://www.zomato.com/blog/annual-report-19

\section{Delivery}

Conveyance income for FY19 is $\$ 155 \mathrm{~m}$ contrasted with $\$ 38 \mathrm{~m}$ in FY18(4x yearly development). It presently contributes $\sim 75 \%$ to our complete income, up from $\sim 55 \%$ in FY18. We presently work the administration in more than 200 urban areas in India, up from 15 urban areas in FY18; and we made about 33m conveyances in March'19( 7x y-oy development).

Over 100k cafés are recorded in India, creating a yearly run-rate GMV of over $\$ 1.5 \mathrm{bn}$. $~ 94 \%$ of these conveyances are satisfied by our $\sim 180 \mathrm{k}$ solid dynamic conveyance armada. 
Unit financial matters of the nourishment conveyance business have progressed significantly. We currently lose Rs 25 for each conveyance, contrasted with Rs 44 for every conveyance in March'18. Our last mile cost per conveyance is currently Rs 65, contrasted with Rs 86 in March'18. The key driver metric of unit financial matters - number of conveyances per rider every hour has gone up to 1.4 from 0.9 a year ago.

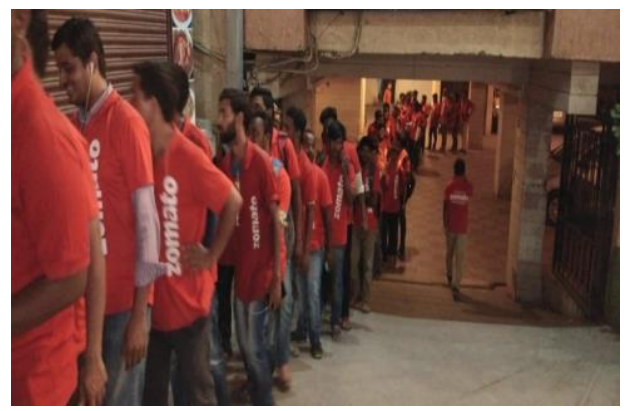

https://www.zomato.com/blog/annual-report-19

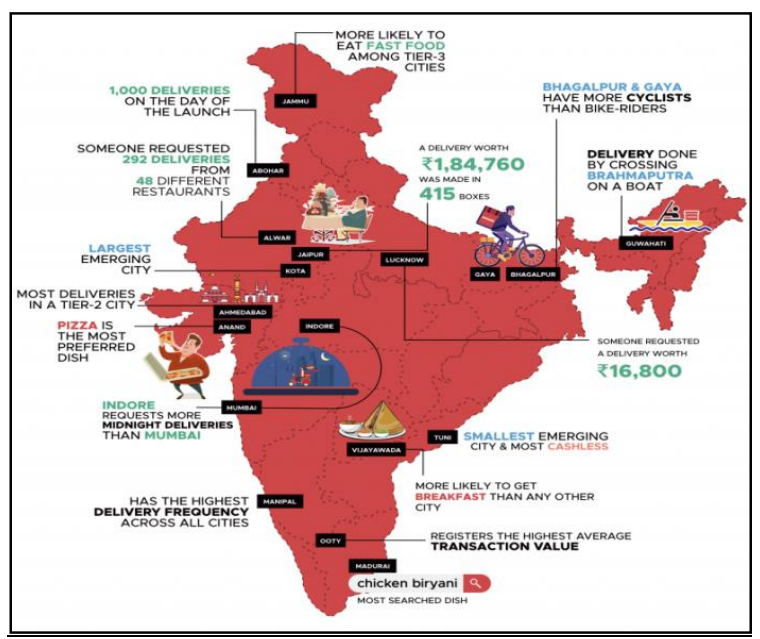

https://economictimes.indiatimes.com/industry/cons-

products/food/so-what-does-urban-india-like-to-eat-zomatojust-gave-you-every-

detail/articleshow $/ 68793746 . \mathrm{cms} ?$ from $=\mathrm{mdr}$

\section{Feeding India}

Better nourishment for more individuals was a key driver in solidifying Feeding India with Zomato. Appetite and nourishment wastage are significant issues to settle, and what better approach to take the test head-on than with persuaded Hunger Heroes that chip away at inventive and practical projects to guarantee all abundance nourishment from different cafés and settings, that would some way or another go to landfills is given to individuals out of luck. Taking care of India has served 20 million suppers with its 5 key projects incorporating 8,500+ volunteers working in 71 urban areas, 50+ network ice chests, and 21 nourishment recuperation vans.

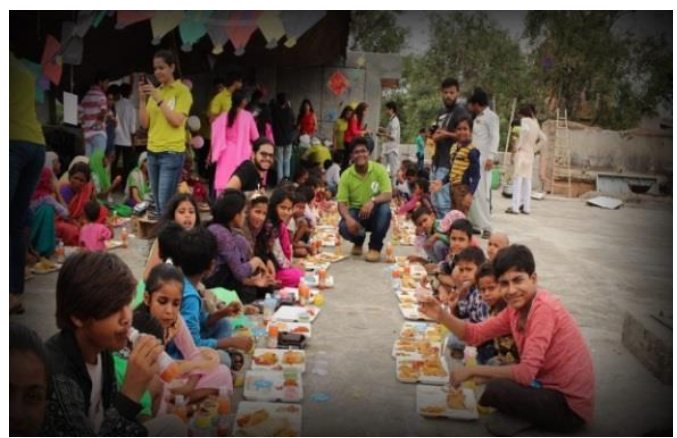

https://www.zomato.com/blog/annual-report-19

\section{Target Audience}

Zomato's intended interest group incorporates individuals between 18 to 35 years old who approach cell phones and are agreeable in utilizing applications. It targets two sorts of clients: The primary gathering incorporates individuals who need to arrange their nourishment home and the subsequent gathering incorporates individuals who like to feast out. IN Lot of cases, these gatherings cover. It offers nourishment conveyance to the individuals who need it conveyed just as offers motivators to individuals to eat out through its Zomato Gold program.

Working experts who need nourishment in their workplaces, understudies who need nourishment in their inns, individuals who don't have time or space to cook for themselves, and individuals who at times prefer to eat outside nourishment all structure a piece of Zomato's intended interest group.

\section{Social Media Marketing}

Zomato is dynamic on Instagram, Facebook and Twitter. Beginning at July 2019, it has 154k followers on Instagram, 1,899,405 supporters and 1.42 Million lovers on Twitter.

\section{Trendy}

Zomato interfaces with the group by posting on polished subjects. The brand fathoms the group's disposition. Consequently, it progresses content which makes customers share it, comment on it and view it again and again. It utilizes in vogue subjects and posts direct pictures in order to work together with watchers on the web.

One of the most essential occasions in the field of sports is the Olympics. During the 2016 Olympics, Zomato posted 


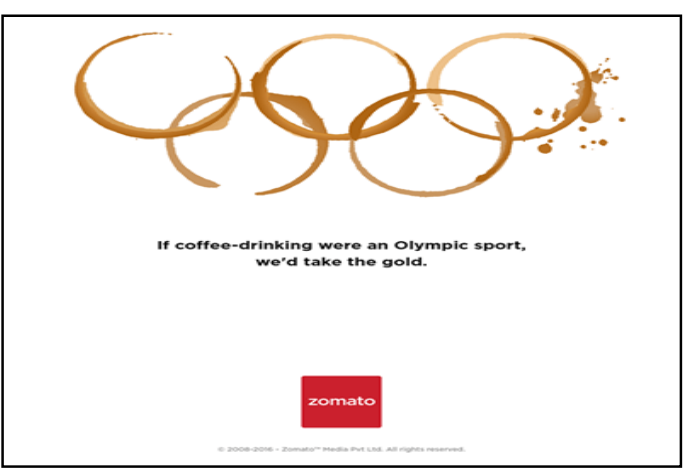

Something like this https://iide.co/case-studies/zomatodigital-marketing-strategy/

Another popular subject of the time was the game "Pokemon Go!" Zomato benefited from that too.

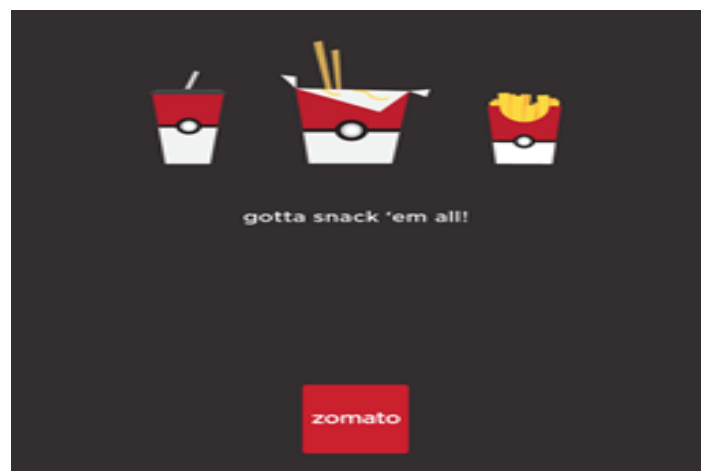

https://iide.co/case-studies/zomato-digital-marketingstrategy/

Zomato gave a bend to the subject of Panama Papers.

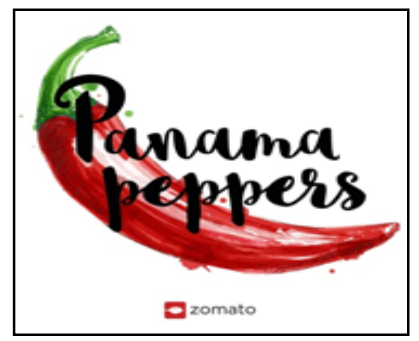

https://iide.co/case-studies/zomato-digital-marketingstrategy/

Posting on the in vogue themes manufactured availability with the crowd. Likely, clients don't wish to think a lot of when they are via web-based networking media. In actuality, clients are there via web-based networking media to appreciate and see interesting substance. And, when such content appears on their news feed, expect your content to be shared. For sure!

\section{Current affairs}

Numerous in the United States and individuals over the world think about the outskirt issue between the United
States and Mexico. Recently chose President Donald Trump had guaranteed that he would guarantee that Mexico would construct the divider between the two countries and pay for it.

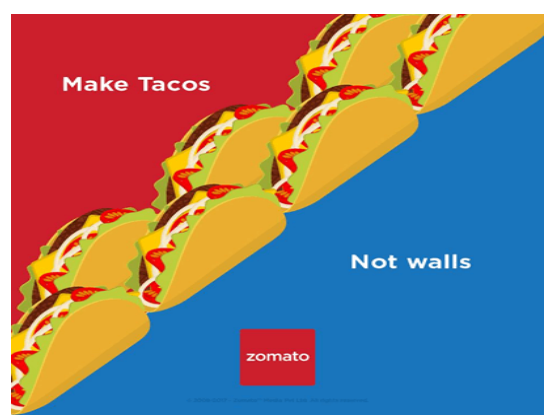

https://iide.co/case-studies/zomato-digital-marketingstrategy/

Zomato had some various plans as a top priority. Current points were identified with nourishment. "Taco darlings" would have doubtlessly responded to this post in huge numbers. Such posts leave an impact on the web based life crowd.

\section{Share of Revenue (Profits)}

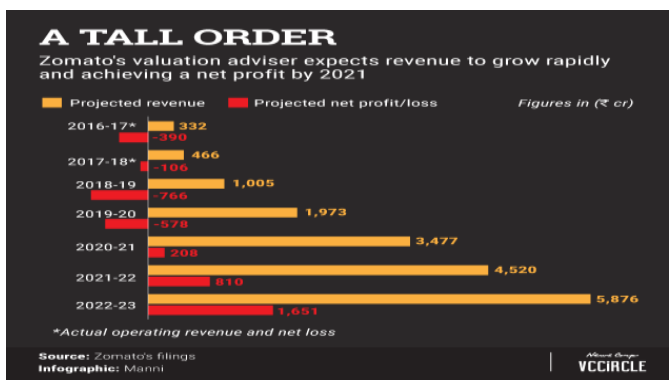

https://www.techcircle.in/2019/02/07/zomato-s-valuation-adviserprojects-profitability-by-2021/

\section{Achievements}

1. Global eatery search and revelation application, Zomato, has recently revealed that its online sustenance requesting administration has just timed more than 2 million requests in the long stretch of March 2017. In correlation, Swiggy timed around 1 million requests a year ago in May.

2. Zomato's online sustenance requesting administration started in 2015 and in just around two years, the organization has come up to process 2 million requests in a single month. Zomato has an overwhelming nearness in India and the UAE, and these volumes are a blend of both the nations.

3. From 12,000 cafés a couple of months back, the number has developed to 18,000 eateries presently 
cooperating with Zomato for online nourishment conveyance. There has likewise furthermore been an upgrade in the client maintenance through improved client experience and administration.

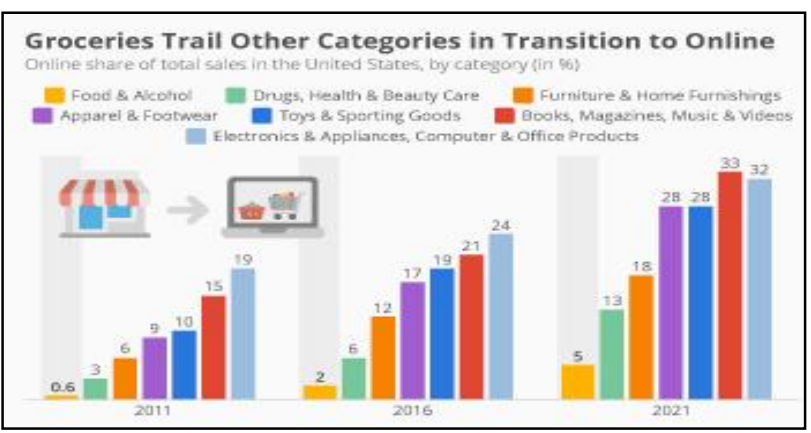

https:/www.statista.com/chart/14852/share-of-online-salesby-product-category/

\section{Future Aim}

Zomato's net edges on a normal request are nearer to 55\%, which is a very decent number and demonstrates that the organization is moving forward way. The online nourishment requesting business has now caught practically $20 \%$ of the organization's income.

With a similar eagerness, the organization is hoping to grow in 13 new nations outside India. Instantly, Zomato has turned into a worldwide brand, with solid nearness in the Middle East and South-East Asia.

\section{Challenges}

1. Most of the youthful age utilizes Zomato to plan for evaluating another café. Zomato appraisals are the fruitful on the grounds that they never uncover how they compute it. What's more, they continue controlling it at their will. You can worry, you can gripe yet can't upset it.

2. They began Zomato requesting at some point back, which can be of unrivaled assistance in the event that you have conveyance decisions. They do remove a strong cut from it which you can attempt to consult with them. This could encourage in acquiring more requests basically in light of an enormous userbase, and the cashbacks that they award.

3. Fierce challenge from brands like Swiggy, Food Panda, Uber eats, and so on.

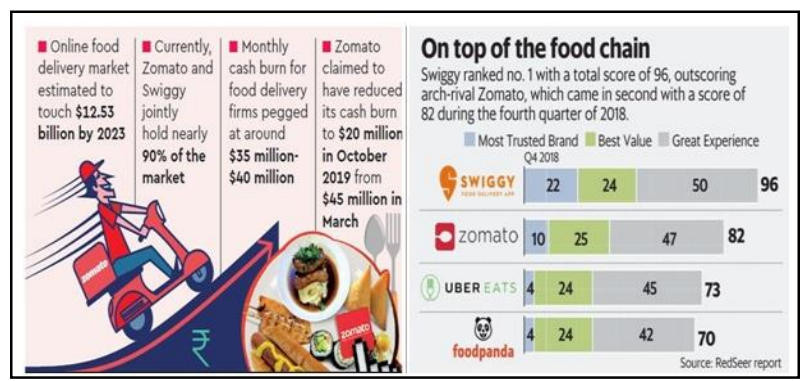

https://www.livemint.com/Companies/WJSpXMp64Q0QLc KLw5tCoK/Swiggy-is-on-top-of-the-online-food-chainshows-survey.html

\section{Swot Analysis}

SWOT analysis is a technique that looks for the following things in a startup and based on it few conclusions are made.

1. Strength

2. Weakness

3. Opportunities

4. Threats

Many conclusions were done from Zomato SWOT ANALYSIS.

\section{Strengths}

1. First mover advantage: One of the most upper hands of Zomato is that it is the underlying mover in a large number of the countries where it is building up itself. Catalogues and various types of café appraisals may exist. Be that as it may, as an application Zomato is remarkable and numerous nations (like India) have cherished the ease of use of the Zomato application.

2. Evergreen exchange: The café exchange is partner evergreen exchange. Of course, there is likewise retreats and elective downturns which may impact the business. Be that as it may, generally speaking, this industry is going to remain around consistently and is basically going to develop with rising discretionary cash flow.

3. Fast expansion: It's thankful that Zomato has turned out to be progressively broad brisk. It is as of now in twenty four nations and is expanding year on year.

4. Fantastic structure of the application: Zomato has oftentimes won honours for its application plan and for its easy to understand nature. The App configuration is shocking and it causes you find eateries close by just as in the region which you are going to visit.

5. Number of clients: Zomato has a high number of clients utilizing their application. Simultaneously, the site additionally has ninety million guests every month approx. With such a significant number of clients 
utilizing the application and site, there are more inputs and thus greater likelihood of discovering better eateries.

6. Excellent subsidizing accessible: Zomato has increased different rounds of financing throughout the years and in light of the fact that it is presently so all around created in numerous nations, there is a decent measure of subsidizing accessible for the application.

7. Multiple acquisitions: Zomato has increased various organizations the majority of which are programming or innovation one-sided.

8. Already turning benefits: In April 2017, Zomato has picked up benefit in each of the 24 nations it was working in. For an industry which is a beginning up and has so much subsidizing, it is an enormous thing to turn beneficial aim many financed or businesses are as yet proclaiming misfortunes even following a time of setting up.

9. Brand equity: Zomato is esteemed at $\$ 1.4$ billion inside 7 years of establishing. That says volumes regarding the vogue and love for the name.

10. Fantastic promoting: You can see Zomato working for its own retail disconnected just as on the web. Its print promotions are humorous and cause a moment to associate with the general population. It is solid on Social media retail and uses a mix of ATL and BTL methodologies to charm and hold clients.

\section{Weakness}

1. Security issues for the application: A noteworthy issue for Zomato in the past has been some wellbeing issues because of which the application was hacked and in any event 17 million client's information was replicated. Such wellbeing issues are a bad dream for web ventures.

2. Still a ton of extension required: Considering that the application has set-up in 24 nations, there is great development. And yet, the application has been set up 7 years back and with the measure of financing available for Zomato, the extension can be much brisk. It is enabling different administrations to create themselves in this specialty before it arrives at their region.

3. Word of mouth and Facebook registration: Besides such applications, in numerous spots informal still bests applications and simultaneously, Facebook registration are a solid challenger wherein open probably won't require Zomato. Hence, it is an application for early adopters however absolutely not for slow pokes.

\section{Opportunities}

1. Further development: The number 1 open door for Zomato to develop is to more nations and set up its base speedier. Administration industry has a noteworthy interfered with that administrations can be replicated quick and absolutely. Accordingly, it is significant for Zomato to build up and develop itself quicker.

2. More acquisitions: There are and were numerous little open in this space. Zomato can obtain a significant number of its rivals and simultaneously, it needs to keep a look on the tech organization and addition any tech development it can get its hands on to continue developing.

3. Cloud eateries: Zomato is thinking of the idea of Cloud cafés wherein eateries won't need to get a physical space to really sell their nourishment items. Next to, they can sell from Zomato.

4. Creating a network: Zomato has a high after however the clients don't connect with one another. Making a discussion and a network out of the clients officially following Zomato can be of a high advantage for the brand.

5. Adoption of the web and smartphones: There is a high increment in the selection of Internet crosswise over creating and immature regions also. Correspondingly, reception of cell phone has likewise expanded. In this way an ever-increasing number of requests and research about cafés can happen online rather than through physical visits.

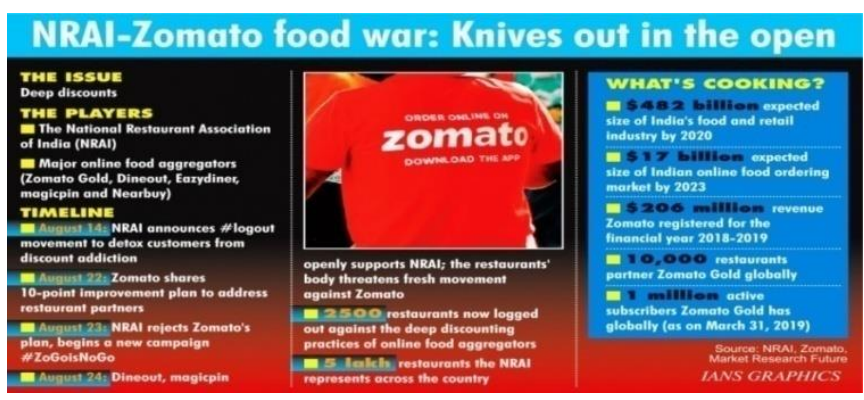

https://www.socialnews.xyz/2019/08/25/infographics-nraizomato-food-war-knives-out-in-the-open-gallery/

\section{Threats}

1. Google's blueprint module: One of the significant dangers Zomato faces right presently is the Schema module of Google wherein google areas itself is getting in café counsel. Indeed, even google landing page demonstrates the google maps page where you can chase for eateries inside your territory. Google being such a major association, Zomato faces enormous challenge from them. 
2. Market adherents and challengers: In the administration business, it is tranquil to repeat the achievement of another administration item or advertising. So also, showcasing adherents and rivals can unhurriedly remove the piece of the pie of Zomato.

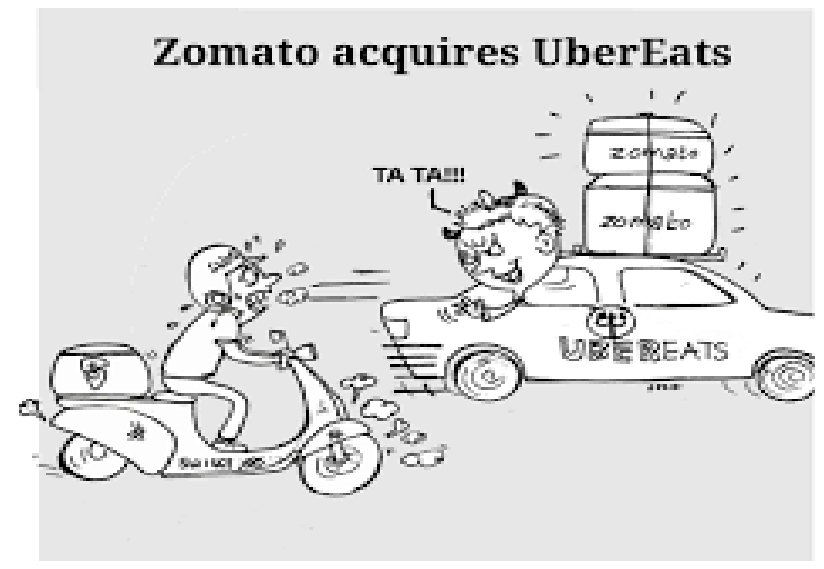

https://www.businessinsider.in/business/startups/news/ubercouldnt-do-what-ola-did-instead-sells-ubereats-to-zomatoto-leave-behind-swiggy/articleshow/73468841.cms

\section{Controversy}

Zomato has confronted a few contentions as of late. Of which a portion of the huge discussion were: -

The sustenance conveyance young men of Zomato have chosen to take to the streets dissenting that the nourishment being conveyed by them harms their otherworldly (religious) opinions. The administrators have questioned conveying meat or pork on the bubbly festivals of Bakrid. On this they would not convey the nourishment since it is against their religious convictions. The conveyance young men's requests incorporate modification of the compensation request which Zomato must stop since it hurt their religious slants. Thusly, both Hindu and Muslim nourishment conveyance administrators have chosen to take to the streets on weekday. Some Muslim eateries have been added their eatery to the online sustenance conveyance application. Anyway Hindu conveyance kid who are denying to conveyance hamburger for the explanation that their profound assumption is being harmed.

Zomato has been punished with Rs 55,000 in conjugation with an inn for conveying non-vegan sustenance not for the single time, however some other time to the lawyer who had requested a veggie lover dish. The request was passed by the supporter court after a city-based lawyer, Shanmukh Deshmukh, griped against the nourishment conveyance stage for erroneously conveying non-vegan sustenance against the veggie lover dish that had been requested. The Additional District Consumer Disputes
Redressal Forum in Pune has asked Zomato and along these lines the inn needed to pay Rs 55,000 pay to the lawyer. The court has allowed a 45-day due date to Zomato and to Hotel Preet Punjabi Swad to pay the sum in 45 days or with $10 \%$ intrigue accordingly. There was a proper understanding between the respondents, that is the reason the court seen both Zomato and the lodging as liable and charged Rs 55,000 as remuneration. Of the entire fine, the Hotel has been approached to pay Rs 50,000 for defective administrations and Rs 5,000 for mental badgering.

Zomato India
Food doesn't have a religion. It is a religion.
पं अमित शुक्ल @NaMo_SARKAAR · 15h
Just cancelled an order on @ZomatolN they allocated a non
hindu rider for my food they said they can't change rider and
can't refund on cancellation I said you can't force me to take
a delivery I don't want don't refund just cancel
Show this thread
10:30 AM · 31 Jul 19 · Twitter Web App

https://www.forbes.com/sites/meghabahree/2019/08/01/food -doesnt-have-a-religion-did-zomato-do-the-rightthing/\#40bd561f48e5

Glimpse of Life at Zomato

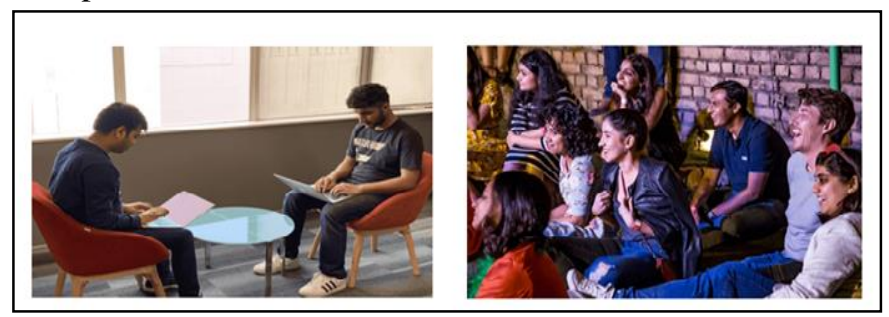

https://www.zomato.com

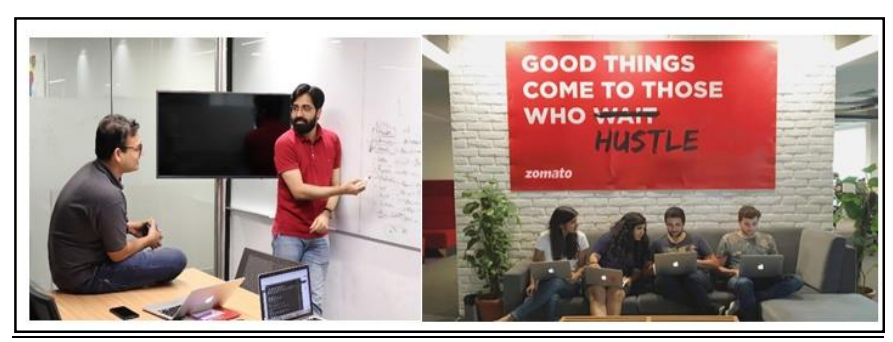

https://www.zomato.com 


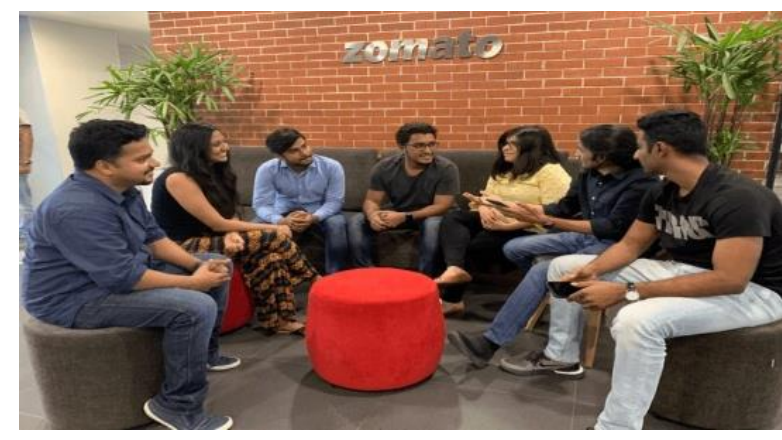

https://www.zomato.com

People behind the Scenes

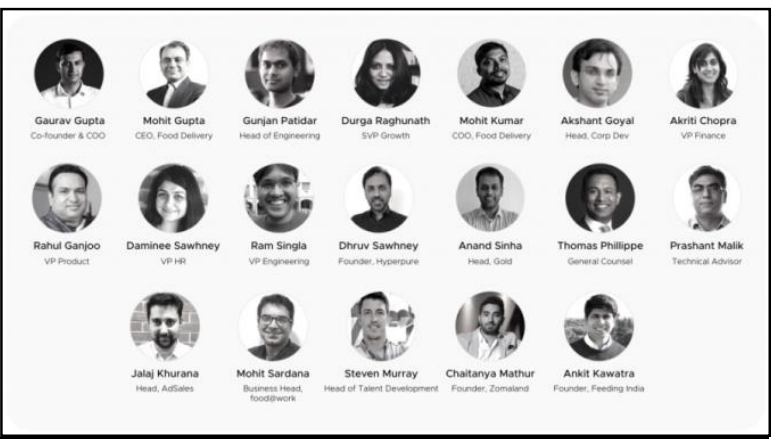

https://www.zomato.com/blog/annual-report-19

\section{Change in Emblem(Logo) in Recent Years}

The logo has been a wellspring of character and after some time, it's been advancing in accordance with our proceeding with conviction framework.

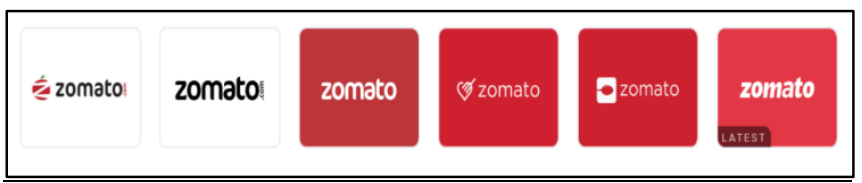

https://www.zomato.com

\section{Conclusion}

1. Zomato had helped a few cafés to pitch their business underneath their space to expand their everyday business.

2. Many conveyance people who do half time/all day occupation got utilized thus helped in expanding the Gross Domestic Produc t(GDP) of our nation
3. Zomato has prepared 2,000,000 online nourishment arranges on its foundation in a solitary month on a promoting cost under $\$ 50000$ every month. Web based requesting has tremendous commitments for Zomato's fund as normal commission rate is practically $8.5 \%$ (for eatery conveyed requests) and from that point organization says the unit financial matters are appallingly positive and net edges on a request are about $55 \%$.

\section{Source of Funding}

None.

\section{Conflict of Interest}

None.

\section{References}

1. www.zomato.com

2. www.businesstoday.in

3. www.republicworld.com

4. economictimes.indiatimes.com

5. www.crunchbase.com

6. smedia2.intoday.in

7. www.indiatoday.in

8. www.marketing91.com

9. www.quora.com

10. www.scribd.com

11. www.trak.in

12. www.jigsimplytalk.com

13. www.iide.co

14. www.lawstreet.co

15. www.forbes.com

16. www.businessinsider.in

17. www.socialnews.xyz

18. www.livemint.com

19. www.statista.com

20. www.techcircle.in

21. www.futureworktechnologies.com

22. www.kalagato.in

How to cite: Panigrahi A, Saha A, Shrinet A, Nauityal M, Gaur V. A Case study on Zomato - The online Foodking of India. J Manag Res Anal. 2020;7(1):25-33. 